\title{
Time-resolved Microwave Conductivity
}

\author{
Part 1.- $\mathrm{TiO}_{2}$ Photoreactivity and Size Quantization
}

\author{
Scot T. Martin, Hartmut Herrmann, $\dagger$ Wonyong Choi and Michael R. Hoffmann* \\ W. M. Keck Laboratories, California Institute of Technology, Pasadena, CA 91125, USA
}

\begin{abstract}
Charge-carrier recombination dynamics after laser excitation are investigated by time-resolved microwave conductivity (TRMC) measurements of quantum-sized (Q-) $\mathrm{TiO}_{2}, \mathrm{Fe}^{\prime \prime \prime}$-doped $\mathrm{Q}-\mathrm{TiO}_{2}, \mathrm{ZnO}$ and CdS, and several commercial bulk-sized $\mathrm{TiO}_{2}$ samples. After pulsed laser excitation of charge carriers, holes that escape recombination react with sorbed trans-decalin within ns while the measured conductivity signal is due to conductionband electrons remaining in the semiconductor lattice. The charge-carrier recombination lifetime and the interfacial electron-transfer rate constant that are derived from the TRMC measurements correlate with the $\mathrm{CW}$ photo-oxidation quantum efficiency obtained for aqueous chloroform in the presence of $\mathrm{TiO}_{2}$. The quantum efficiencies are $0.4 \%$ for $\mathrm{Q}-\mathrm{TiO}_{2}, 1.6 \%$ for Degussa P25, and $2.0 \%$ for $\mathrm{Fe}^{\prime \prime \prime}$-doped $\mathrm{Q}-\mathrm{TiO}_{2}$. The lower quantum efficiencies for $\mathrm{Q}-\mathrm{TiO}_{2}$ are consistent with the relative interfacial electron-transfer rates observed by TRMC for $\mathrm{Q}-\mathrm{TiO}_{2}$ and Degussa P25. The increased quantum efficiencies of $\mathrm{Fe}^{\prime \prime \prime}$-doped Q-TiO 2 and the observed TRMC decays are consistent with a mechanism involving fast trapping of valence-band holes as $\mathrm{Fe}^{\mathrm{IV}}$ and inhibition of charge-order recombination.
\end{abstract}

When the crystallite dimension of a semiconductor particle falls below a critical radius of $c a .10 \mathrm{~nm}$, the charge carriers appear to behave quantum-mechanically as a simple particle in a box. ${ }^{1-6}$ As a result of this confinement, the bandgap increases and the band edges shift to yield larger redox potentials. The solvent reorganization Gibbs energy for charge transfer to a substrate, however, remains unchanged. The increased driving force and the unchanged solvent reorganization Gibbs energy in size-quantized systems are expected to increase the rate constant of charge transfer in the normal Marcus region. ${ }^{7-9}$ Thus, the use of size-quantized semiconductor $\mathrm{TiO}_{2}$ particles may result in increased photoefficiencies for systems in which the rate-limiting step is charge transfer. ${ }^{10,11}$ One such system is the oxidation of many common organic pollutants in the presence of $\mathrm{TiO}_{2}$ irradiated with bandgap illumination. ${ }^{12-15}$

The use of size-quantized semiconductors to increase photoefficiencies is supported by several studies. ${ }^{10,16-19}$ However, in other work, size-quantized semiconductors have been found to be less photoactive than their bulk-phase counterparts. ${ }^{11,20}$ In the latter cases, surface speciation and surface defect density appear to control photoreactivity. ${ }^{21-23}$ The positive effects of increased overpotentials (i.e. difference between $E_{\mathrm{vb}}$ and $E_{\text {redox }}$ ) on quantum yields can be offset by unfavourable surface speciation and surface defects due to the method of preparation of size-quantized semiconductor particles.

In the present study, the photodegradation of several chlorinated compounds in the presence of $\mathrm{Q}-\mathrm{TiO}_{2}$ are used as control reactions to study the size-quantization effect on photoreactivity. The stoichiometry of the reactions is as follows:

$$
\begin{aligned}
\mathrm{C}_{x} \mathrm{H}_{y} \mathrm{Cl}_{z}+ & \left(x+\frac{y-z}{4}\right) \mathrm{O}_{2} \\
& \underset{h v_{,} \mathrm{TiO}_{2}}{\longrightarrow} x \mathrm{CO}_{2}+z \mathrm{H}^{+}+z \mathrm{Cl}^{-}+\left(\frac{y-z}{2}\right) \mathrm{H}_{2} \mathrm{O}
\end{aligned}
$$

The photodegradations of chloroform, ${ }^{24}$ pentachlorophenol, ${ }^{25.26}$ and 4-chlorophenol ${ }^{27-31}$ with Degussa P25 (i.e. a bulk-phase $\mathrm{TiO}_{2}$ consisting of $80 \%$ anatase and $20 \%$ rutile)

† Present address: Institut für Physikalische und Theoretische Chemie der Universität GH Essen, Germany. have been studied previously. P25 is a commercial form of $\mathrm{TiO}_{2}$ that generally has a higher photoreactivity than other available forms of $\mathrm{TiO}_{2}$

The variable photoefficiencies of the different forms of $\mathrm{TiO}_{2}$ are related to their fundamental charge-carrier dynamics. In order to verify this relationship, we investigate the charge-carrier dynamics of $\mathrm{Q}-\mathrm{TiO}_{2}$ and $\mathrm{P} 25$ by TRMC measurements. ${ }^{32-38}$ In a typical TRMC experiment, separated charge carriers, which are generated by a laser pulse, lead to a perturbation of the initial microwave absorbance. ${ }^{33.39}$ The temporal decay of the conductivity signal (i.e. microwave absorbance) reflects the lifetime of the photogenerated carriers. The technique has only recently been expanded to semiconductor particles, ${ }^{34-38,40,41}$ for which conventional techniques (e.g. photoconductivity) are often not possible owing to the necessity for electrode contacts. Efforts have been made here to provide experimental details of the TRMC technique, including the development of a novel sample holder that is usable in conjunction with conventional lasers.

\section{Experimental}

\section{Preparation}

Q-TiO 2 was prepared by the controlled hydrolysis of titanium(Iv) tetraisopropoxide. ${ }^{42} 5 \mathrm{ml}$ Ti $\left[\mathrm{OCH}\left(\mathrm{CH}_{3}\right)_{2}\right]_{4}$ (Aldrich, 97\%) dissolved in $100 \mathrm{ml}$ isopropyl alcohol was added dropwise (90-120 min) with vigorous stirring to $900 \mathrm{ml}$ doubly distilled water $\left(2^{\circ} \mathrm{C}\right)$ adjusted to $\mathrm{pH} 1.5$ with $\mathrm{HNO}_{3}$. The transparent colloid can be stored for over one year in a cold room $\left(4{ }^{\circ} \mathrm{C}\right)$ without coagulation. To obtain a powdered sample, $150 \mathrm{ml}$ of the colloidal solution was evaporated $\left(35^{\circ} \mathrm{C}\right.$ ) using a Rotavapor (model R110). The resulting film was dried with an $\mathrm{N}_{2}$ stream to yield a white powder. $\mathrm{Fe}^{\mathrm{III}}$ doped $\mathrm{Q}-\mathrm{TiO}_{2}$ was prepared by a similar procedure in the presence of $\mathrm{Fe}\left(\mathrm{NO}_{3}\right)_{3}$ to give an atomic doping level of $1 \%$. Full incorporation of $\mathrm{Fe}^{\mathrm{III}}$ into the lattice has been shown by other workers. ${ }^{43,44}$

The bulk-phase semiconductors used were $\mathrm{ZnO}$ (Baker), $\alpha$ $\mathrm{Fe}_{2} \mathrm{O}_{3}$ (hematite, Fisher), CdS (Alfa), and $\mathrm{TiO}_{2}$ (Degussa P25 and Sachtleben Chemie S7, S13, S17, S18, S21 and S24). We used two separate batches of Degussa P25, which were obtained in 1988 (P25-A) and 1993 (P25-B). 


\section{Characterization}

Particle sizes were determined by a Philips EM 430 transmission electron microscope (TEM) at $300 \mathrm{kV}$. Samples for TEM were prepared by placing a drop onto a copper mesh substrate covered with a carbon film, followed by removal of the excess liquid with a piece of thin filter paper and drying for $30 \mathrm{~s}$ under a tungsten lamp. A representative TEM micrograph is shown in Fig. 1. The sizes of the Q-particles ranged from 2 to $4 \mathrm{~nm}$ with a lattice spacing of $3.6 \pm 0.1 \AA$. This spacing was in good agreement with the anatase (101) phase lattice spacing of $3.51 \AA \AA^{45} \mathrm{X}$-Ray diffraction (XRD) analysis was carried out with powdered samples on a Scintag PAD5 model DMC-008 using $35 \mathrm{kV}, 20 \mathrm{~mA} \mathrm{Cu}-\mathrm{K} \alpha(1.54 \AA)$ radiation. The diffraction pattern of the $\mathrm{Q}$-sized $\mathrm{TiO}_{2}$ was also characteristic of anatase. The observed line broadening due to the presence of small crystallites was analysed by the Scherrer equation ${ }^{46}$ and showed that the particles were 3-4 $\mathrm{nm}$ in diameter.

Degussa P25 has been characterized previously. ${ }^{47,48} 30 \mathrm{~nm}$ crystallites composed of $80 \%$ anatase and $20 \%$ rutile aggregate to form particles with an average diameter of $1 \mu \mathrm{m}$. For the TRMC experiments, P25 $\left(1.44 \mathrm{~g}^{-1}\right)$ was suspended in $\mathrm{HNO}_{3}$ (pH 1.5) and rotary evaporated to a dry powder. The characterization of the $\mathrm{TiO}_{2}$ samples obtained from Sachtleben Chemie is shown in Table $1 .^{49}$

\section{Irradiation}

Steady-state photolyses were carried out in a slurry reactor to determine the initial rate constants for the degradation of chloroform (Baker), dichloroacetic acid (Spectrum Chemical Manufacturing, Inc.), carbon tetrachloride (Baker), pentachlorophenol (Aldrich), and 4-chlorophenol (Aldrich). Irradiations were performed with a $1000 \mathrm{~W}$ Xe arc lamp (Spindler and Hoyer). The IR component of the incident light was

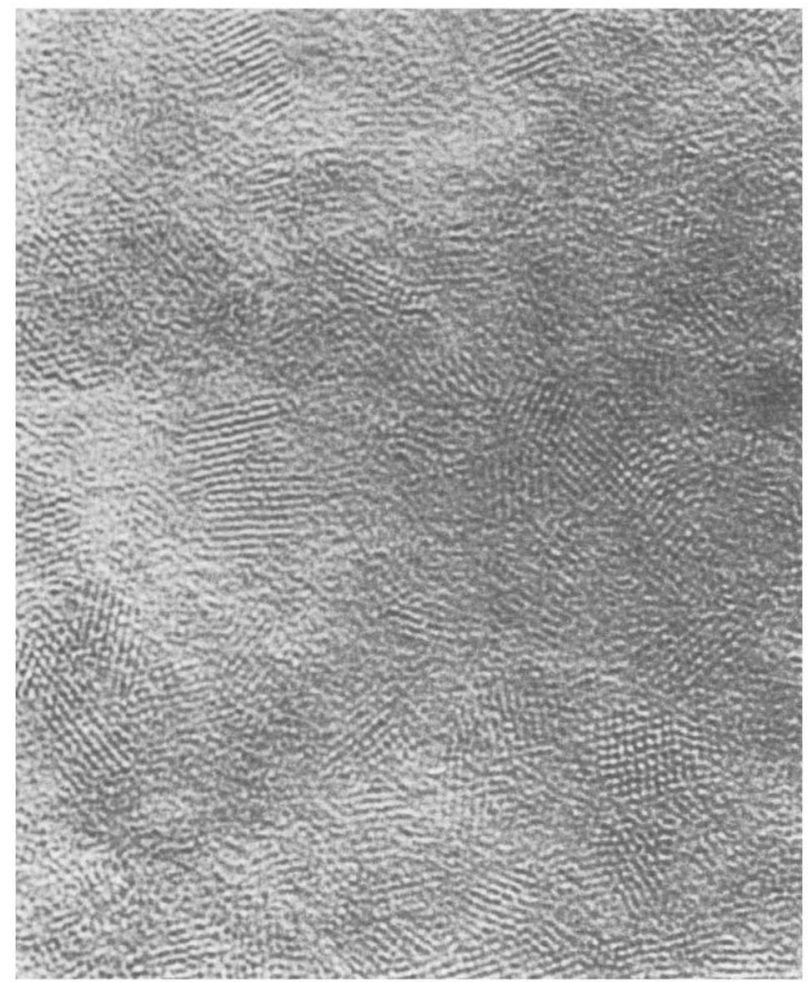

Fig. 1 TEM micrograph of quantum-sized $\mathrm{TiO}_{2}$
Table 1 TRMC results and photoreactivity data of commercial samples of $\mathrm{TiO}_{2}$

\begin{tabular}{lcccc}
\hline & surface area & $\begin{array}{c}\text { relative } \\
\text { charge-carrier } \\
\text { concentration } \\
\text { sample }\end{array}$ & $\begin{array}{c}\mathrm{m}^{2} \mathrm{~g}^{-1} \\
\text { efficiency }\end{array}$ & $\begin{array}{c}\text { interfacial electron- } \\
\text { transfer rate } \\
\text { constant } / \mathrm{ms}^{-1}\end{array}$ \\
\hline S7 & 85 & $0.25 \%$ & 0.60 & 0.12 \\
S13 & 90 & $0.24 \%$ & 1.28 & 0.06 \\
S17 & 380 & $0.07 \%$ & 0.12 & $\mathrm{n} / \mathrm{a}$ \\
S18 & 230 & $0.26 \%$ & 0.52 & 0.16 \\
S21 & 280 & $0.44 \%$ & 0.52 & 0.34 \\
S24 & 30 & $0.04 \%$ & 0.16 & $\mathrm{n} / \mathrm{a}$ \\
S25-B & 50 & $0.39 \%$ & 0.92 & 0.13 \\
\hline
\end{tabular}

${ }^{a}\left[\mathrm{HCCl}_{3}\right]=3.2 \mathrm{mmol} \mathrm{l}^{-1}\left[\mathrm{TiO}_{2}\right]=0.5 \mathrm{~g} \mathrm{l}^{-1}, I=214 \mu \mathrm{ein} 1^{-1} \mathrm{~min}^{-1}$, $\lambda=320 \pm 5 \mathrm{~nm}$, air equilibrated, $\mathrm{pH} 4-6$.

removed by a $10 \mathrm{~cm}$ water filter. Depending upon the experiment, wavelengths were selected with an interference filter (Oriel, $\lambda=320 \pm 5 \mathrm{~nm}$ ), a longpass filter (Oriel, $\lambda>320 \mathrm{~nm}$ ), or a bandpass filter (Corning 7-60-1, 320< $<<380 \mathrm{~nm}$ ). Light intensity was adjusted with neutral density filters. The chemical actinometer Aberchrome $540\{[(E)-\alpha-(2,5-$ dimethyl3-furyl)ethylidene]-3-isopropylidenesuccinic anhydride $\}$ was used to determine the incident light intensity, which was found to vary between 100 and $200 \mu \mathrm{mol}^{-1} \mathrm{~min}^{-1}$ with the interference filter in place and to be $1000 \mu^{-1} \mathrm{~mol}^{-1} \mathrm{l}^{-1} \mathrm{~min}^{-1}$ with the longpass filter. ${ }^{50}$ Aqueous suspensions $(35 \mathrm{ml})$ of the chlorinated compounds and $\mathrm{TiO}_{2}\left(1.0 \mathrm{~g} \mathrm{l}^{-1}\right)$ were prepared and the $\mathrm{pH}$ was adjusted by the addition of $\mathrm{HNO}_{3}$. Initial degradation rates were determined by the total $\mathrm{Cl}^{-}$release after $1 \mathrm{~h}$ illumination in the case of $\mathrm{HCCl}_{3}\left(63 \mathrm{mmol}^{-1}\right)$, DCA $\left(4.8 \mathrm{mmol}^{-1}\right)$ and $\mathrm{CCl}_{4}\left(5.1 \mathrm{mmol} \mathrm{l}^{-1}\right)$ and by HPLC (Hewlett Packard Series II 1090 Liquid Chromatograph) analysis for PCP $\left(60 \mu \mathrm{mol} \mathrm{l}^{-1}\right)$ and 4-CP $\left(100 \mu \mathrm{mol} 1^{-1}\right)$. Chloride concentrations were determined with an Orion chloride-selective electrode (model no. 9617B).

\section{TRMC Measurements}

A schematic diagram of the microwave conductivity apparatus is shown in Fig. 2. A Gunn diode microwave source (100 $\mathrm{mW}, 38.3 \mathrm{GHz}$, MACOM Inc.), a PIN diode microwave detector, a Comlinear model CLC206AI amplifier, a TEK 2440 digitizing oscilloscope, and an HP $432 \mathrm{~A}$ power meter were coupled into the TRMC unit. The source, detector, and amplifier were enclosed in aluminium Faraday cages. The waveguide system was R-band WR-28 $(0.711 \mathrm{~cm} \times 0.356 \mathrm{~cm})$. A Lambda Physik excimer laser (LPX 120) was used for a $308 \mathrm{~nm}, 50 \mathrm{~ns}$ pulse excitation source. Layered metal mesh

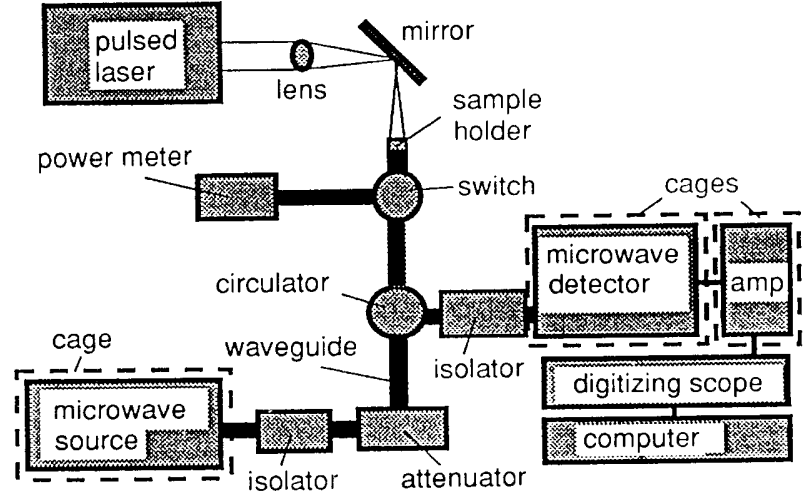

Fig. 2 Schematic diagram of the apparatus for TRMC measurements 
interposed between the laser and the sample was used to control incident light intensity, which was $4.5 \mathrm{~mJ}$ per pulse otherwise stated. In a typical experiment, between 32 and 256 conductivity decays were averaged to improve the signal-tonoise ratio. The digitized data were transferred to a computer for storage and data analysis. The data were collected on four timescales (200 ns div. ${ }^{-1}, 2 \mu \mathrm{siv}^{-1}, 200 \mu \mathrm{s} \mathrm{div.}^{-1}$ and 10 ms div. $\left.{ }^{-1}\right)$. The transients were reproducible within $5 \%$ error.

The sample holder, which was designed especially for this series of experiments, is shown in Fig. 3. The top plate (i.e. short) has seven slits cut orthogonal to the propagating microwave mode so that the laser light can enter the waveguide while the microwaves are reflected back into the waveguide. The sample was prepared as a thick paste supported in trans-decalin (Aldrich). The paste was moulded into a Teflon holder with an illuminated surface area of $13.9 \mathrm{~mm}^{2}$. The Teflon holder was fitted into the waveguide at a distance of $1.65 \mathrm{~mm}$ from the short plate. The holder was positioned by the use of an aluminium block inserted from the rear of the waveguide upon which the holder was pressed.

The principles of the TRMC experiment have been discussed previously. ${ }^{32,33,51}$ Microwaves from the source pass through the sample and impact on the PIN diode detector, which then transforms the incident microwave power into a voltage for input to the oscilloscope. The absorbed microwave power is directly proportional to the conductivity of the sample, $\sigma$, for low-conductivity samples. ${ }^{32}$ The proportionality constant, $A$, is specific to the geometry of the apparatus and the sample, and it is determined by calibration. The change in absorbed microwave power, $\Delta P$, due to a change in conductivity, $\Delta \sigma$, caused by carrier excitation is given by eqn. (1) where $P$ is the initial microwave power level.

$$
\frac{\Delta P(t)}{P}=A \Delta \sigma(t)
$$

The microwave power is transformed into a voltage, $V$, by the PIN diode detector as $P=V^{n}$. For perturbations below $3 \%$, the response is linear, as shown in eqn. (2). ${ }^{32}$

$$
\frac{\Delta P}{P}=n\left(\frac{\Delta V}{V}\right)
$$

The proportionality constant, $n$, is typically between 1 and 2 and is found by calibration. Substitution of eqn. (1) and eqn. (2) results in eqn. (3).

$$
\Delta V(t)=\left(\frac{V A}{n}\right) \Delta \sigma(t)
$$

The temporal behaviour of the voltage observed at the digitizer and the conductivity of the sample are thus proportional.

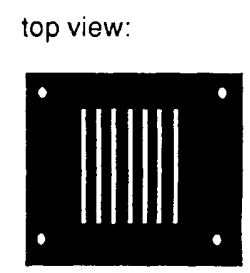

7 slit short: side view:

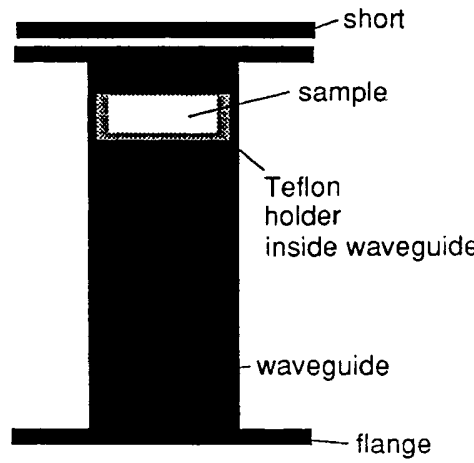

Fig. 3 Sample holder for powdered semiconductor

\section{Principles of TRMC}

When free charge carriers couple to the electric field of the microwaves, absorption occurs. ${ }^{39}$ The strength of the interaction is expressed in terms of mobilities. The mobilities of a free electron in $\mathrm{He}$ gas $\left(1 \mathrm{~m}^{2} \mathrm{~V}^{-1} \mathrm{~s}^{-1}\right)$, of free carriers in $\mathrm{Si}$ (0.2), of a hopping electron in an organic compound $\left(10^{-3}\right.$ $\left.10^{-4}\right)$, of ions in solution $\left(10^{-7}-10^{-8}\right)$, and of dipole moments $\left(10^{-9}\right.$ to $\left.10^{-12}\right)$ reflect the relative coupling efficiencies at microwave frequencies. ${ }^{33}$ The interpretation of TRMC measurements of polar molecules in non-polar solvents and of free carriers in silicon are generally understood; $32,33,51-53$ however, the interpretation of the conductivity decays of semiconductor particles with low carrier mobilities $\left(<10^{-4} \mathrm{~m}^{2} \mathrm{~V}^{-1} \mathrm{~s}^{-1}\right)$ has not been addressed previously. In high-mobility semiconductors such as GaAs $\left(8900 \mathrm{~m}^{2} \mathrm{~V}^{-1} \mathrm{~s}^{-1}\right), \mathrm{Si}$ (1950), $\mathrm{ZnO}$ (380) or CdS (390), the microwave absorption can be attributed to free carriers. ${ }^{32,54}$ Furthermore, for these semiconductors, with the exception of $\mathrm{ZnO}$, the electron mobility is several times larger than the hole mobility so that the observed conductivity decay is attributable entirely to free electrons. For lowmobility semiconductors, such as $\mathrm{TiO}_{2}\left(10^{-4}-10^{-5} \mathrm{~m}^{2} \mathrm{~V}^{-1}\right.$ $\left.\mathrm{s}^{-1}\right)^{55}$ and $\alpha-\mathrm{Fe}_{2} \mathrm{O}_{3}\left(10^{-5}\right),{ }^{56}$ the microwave absorbance may not be due exclusively to free carriers. The mobility of a shallow trap may be similar to that of a hopping electron in an organic compound $\left(10^{-3}-10^{-4} \mathrm{~m}^{2} \mathrm{~V}^{-1} \mathrm{~s}^{-1}\right)$; therefore, in these cases free and shallowly trapped carriers may simultaneously contribute to the conductivity decay of $\mathrm{TiO}_{2}$. Examples of shallowly trapped carriers in $\mathrm{TiO}_{2}$ at $25^{\circ} \mathrm{C}$ include small polarons ${ }^{57}$ and electrons on $\mathrm{Ti}^{\mathrm{III}}$ sites. $^{40}$

\section{Results}

Initial degradation rates of chloroform as a function of the concentration of chloroform and the type of $\mathrm{TiO}_{2}$ are illustrated in Fig. 4. At the solubility limit for aqueous chloroform $\left(63 \mathrm{mmol}^{-1}\right)$, the quantum yield for chloride release is $0.4 \%$ for $\mathrm{Q}-\mathrm{TiO}_{2}$ and $1.6 \%$ for $\mathrm{P} 25-\mathrm{A}$. Doping of the $\mathrm{Q}-\mathrm{TiO}_{2}$ with $\mathrm{Fe}^{\mathrm{III}}$ at 1.0 atom $\%$ shows an increase in the quantum yield to $2.0 \%$. Initial degradation quantum efficiencies of chloroform, dichloroacetic acid (DCA), carbon tetrachloride, pentachlorophenol (PCP) and 4-chlorophenol (4-CP) are shown in Table 2 for Q- $\mathrm{TiO}_{2}$ and P25-A. The quantum efficiencies obtained with $\mathrm{Q}-\mathrm{TiO}_{2}$ are less than those obtained with P25-A.

The observed microwave conductivity decays of $\mathrm{ZnO}, \mathrm{CdS}$, P25 and $\mathrm{Al}_{2} \mathrm{O}_{3}$ are shown in Fig. 5. Since the signal strengths and timescales of decay vary over several orders of

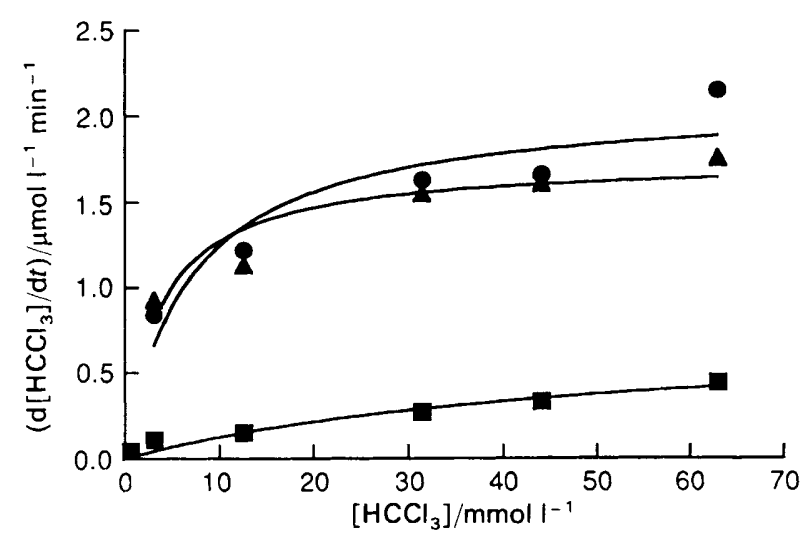

Fig. 4 Degradation rate of chloroform as a function of concentration. $\Delta, \mathrm{P} 25-\mathrm{A}: \mathbf{Q}, \mathrm{Q}-\mathrm{TiO}_{2} ; 0, \mathrm{Fe}^{\mathrm{III}}$ doped $(1 \%) \mathrm{Q}-\mathrm{TiO}_{2}$. Conditions: pH $2.8\left(\mathrm{HNO}_{3}\right),\left[\mathrm{TiO}_{2}\right]=0.5 \mathrm{~g} \mathrm{l}^{-1}, I=110 \mu \mathrm{mol} \mathrm{l}^{-1} \mathrm{~min}^{-1}$ $(\lambda=320 \pm 5 \mathrm{~nm})$, air equilibrated. 
Table 2 Quantum efficiencies of $\mathrm{Q}^{-\mathrm{TiO}_{2}}$ and Degussa P25-A towards photomineralization of chlorinated compounds

\begin{tabular}{lcccr}
\hline \multicolumn{1}{c}{ substrate } & concentration/mmol 1-1 & measurement & $\Phi_{\mathbf{Q}_{\text {-TiO }}}(\%)$ & $\Phi_{\mathbf{P}_{25-A}}(\%)$ \\
\hline chloroform $^{a}$ & 63 & {$\left[\mathrm{Cl}^{-}\right]$} & 0.4 & 1.6 \\
dichloroacetic acid $^{a}$ & 4.8 & {$\left[\mathrm{Cl}^{-}\right]$} & 1.1 & 23.9 \\
carbon tetrachloride $^{a, b}$ & 5.1 & {$\left[\mathrm{Cl}{ }^{-}\right]$} & 0.4 & 3.1 \\
pentachlorophenol $^{a}$ & 60 & {$[\mathrm{PCP}]$} & 0.3 & 0.4 \\
4-chlorophenol $^{c}$ & 100 & {$[4-\mathrm{CP}]$} & 0.4 & 1.8 \\
\hline
\end{tabular}

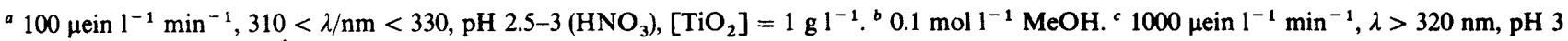
$\left(\mathrm{HNO}_{3}\right),\left[\mathrm{TiO}_{2}\right]=1 \mathrm{~g}^{-1}$

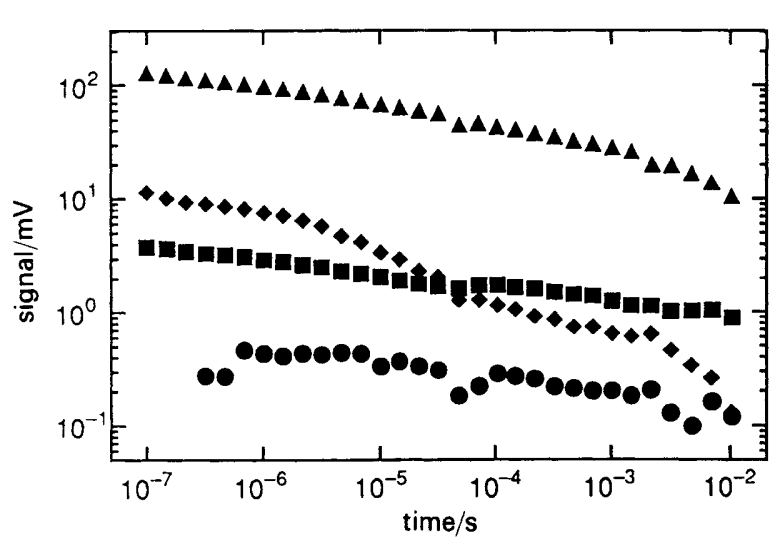

Fig. 5 Double log plot of time-resolved microwave conductivity decay of several powdered semiconductors supported in transdecalin. $\mathbf{A}, \mathrm{ZnO} ; \bullet, \mathrm{CdS} ; \mathbf{\square}, \mathrm{P} 25-\mathrm{A} ; \boldsymbol{\bullet}, \mathrm{Al}_{2} \mathrm{O}_{3}$.

magnitude, the data are represented in $\log -\log$ form. Alumina $\left(\alpha-\mathrm{Al}_{2} \mathrm{O}_{3}\right)$, which has a bandgap of $9.5 \mathrm{eV}$, serves as a blank for the apparatus and indicates the minimum detection limit. ${ }^{35}$ For direct comparison, $\mathrm{NaCl}$ shows a similar decay profile. The relative rates of decay can be characterized by the half-life signal decay. For $\mathrm{ZnO}$, the first half-life is $6.6 \mu \mathrm{s}$ and the second is $164 \mu \mathrm{s}$. For CdS, the first half-life is $60 \mathrm{~ns}$, the second is $770 \mathrm{~ns}$, and the third is $9.2 \mu \mathrm{s}$. For P25-A, the first half-life is $1.1 \mu$ s and the second is $1.7 \mathrm{~ms}$. Several investigators have reported that the half-lives for conductivity decay in $\mathrm{CdS}$ and $\mathrm{TiO}_{2}$ increase as the decay time increases; our observations are consistent with these previous reports. ${ }^{30,40,41}$ For example, Schindler and Kunst reported a $\tau_{1 / 2}$ for P25 for $2.0 \mu$ s for the conductivity observed at 100 ns. ${ }^{40}$ This value agrees reasonably with our value of $1.1 \mu$ s for P25-A.

The initial degradation rates of chloroform as a function of light intensity are shown in Fig. 6. Two linear regions are

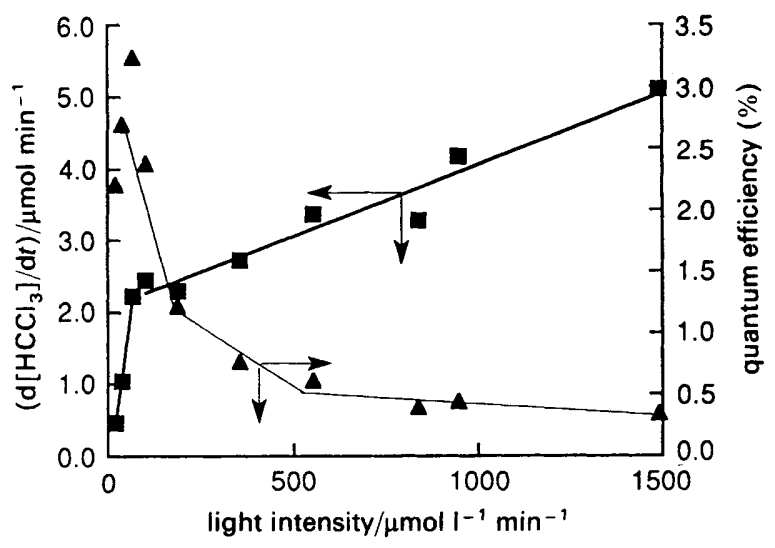

Fig. 6 Degradation rate of chloroform as a function of light intensity. Conditions: $\mathrm{pH} 11(\mathrm{NaOH}),[\mathrm{P} 25-\mathrm{A}]=0.5 \mathrm{~g} \mathrm{t}^{-1}, 320<\lambda$ / $\mathrm{nm}<380$, air equilibrated. observed, and the cross-over occurs at $150 \mu \mathrm{mol}^{-1} \mathrm{~min}^{-1}$ The quantum efficiencies vary from $2.5 \%$ for $I=50 \mu \mathrm{mol}^{-1}$ $\min ^{-1}$ to $0.3 \%$ for $I=1490 \mu \mathrm{mol}^{-1} \min ^{-1}$. In Fig. 7, the time-resolved conductivities at $100 \mathrm{~ns}$ of P25-A prepared in $\mathrm{HNO}_{3}$ and trans-decalin are plotted as a function of the incident laser pulse energy. Two linear regions are identified with an apparent cross-over at a pulse energy of $6 \mathrm{~mJ}$.

Representative conductivity decays for TRMC measurements of S7, S13, S17, S18, S21, S24 and P25-B are shown in Fig. 8. For most samples, the interfacial electron-transfer rate constants reported in Tables 1 and 3 are calculated by singleexponential fits of the conductivity data. However, in the case of S17 and S24, the signal-to-noise ratio is too low to facilitate an exponential fit of the data. Discrepancies between similar samples in Tables 1 and 3 are due to differences in the pre-amplifier, the incident pulse energy $(2.5 \mathrm{~mJ}$ in Table 1), CW illumination intensity, and batches of P25.

A contour plot of the quantum efficiencies reported in Table 1 as a function of the recombination lifetime and the interfacial electron-transfer rate constant is shown in Fig. $9(a)$. The arrows on the data points for S17 and S24 indicate that the interfacial electron-transfer rate constant is unknown. The charge-carrier recombination lifetimes (vide infra) are the charge-carrier concentrations (at $100 \mathrm{~ns}$ ) report-

Table 3 TRMC results for Q- $\mathrm{TiO}_{2}, \mathrm{Fe}^{\mathrm{III}}$-doped Q-TiO, P25-A $\left(\mathrm{No} \mathrm{NO}_{3}{ }^{-}\right.$) and $\mathrm{P} 25-\mathrm{A}\left(\mathrm{NO}_{3}{ }^{-}\right)$

\begin{tabular}{lcc}
\hline \multicolumn{1}{c}{ sample } & $\begin{array}{c}\text { relative } \\
\text { charge-carrier } \\
\text { concentration } \\
\text { (at } 100 \mathrm{~ns}) / \mathrm{mV}\end{array}$ & $\begin{array}{c}\text { interfacial } \\
\text { electron-transfer } \\
\text { rate constant } / \mathrm{ms}^{-1}\end{array}$ \\
\hline $\mathrm{Q}^{-\mathrm{TiO}_{2}}$ & 3.1 & 0.052 \\
$\mathrm{Fe}^{\mathrm{iII}}$-doped $\mathrm{Q}^{-\mathrm{TiO}_{2}}$ & 1.0 & 0.078 \\
$\mathrm{P}_{2}$ 25-A (No $\mathrm{NO}_{3}{ }^{-}$) & 4.0 & 0.056 \\
$\mathrm{P} 25-\mathrm{A}\left(\mathrm{NO}_{3}{ }^{-}\right)$ & 2.9 & 0.065 \\
\hline
\end{tabular}

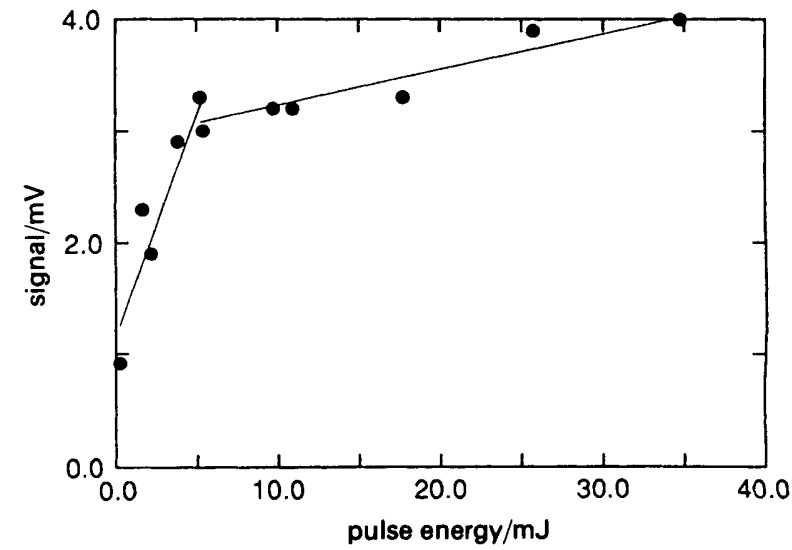

Fig. 7 Effect of the incident laser pulse energy on the initial (100 ns) conductivity of P25-A prepared in $\mathrm{HNO}_{3}$ and trans-decalin 

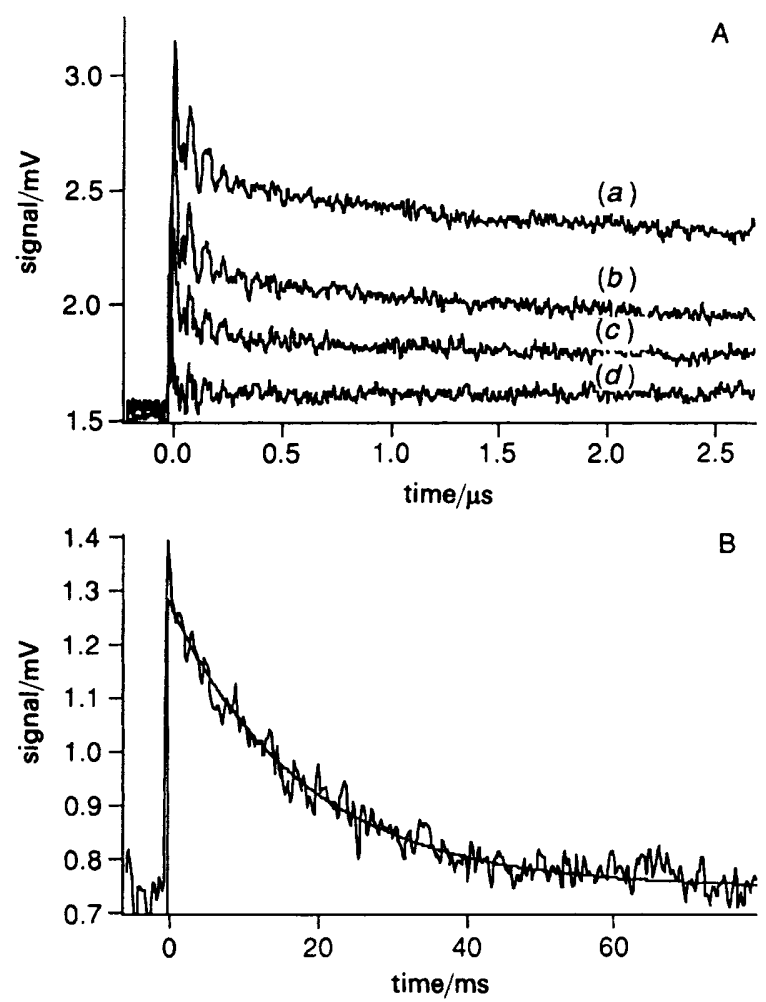

Fig. 8 Representative conductivity decays of Sachtleben and Degussa TiO, powders. A, (a) S13, (b) P25-B, (c) S18 and (d) S17, $2 \mu$ s div. $^{-1}$. (b) Exponential fit of conductivity decay for P13, $k=0.056$ $\mathrm{ms}^{-1}, 10 \mathrm{~ms} \mathrm{div.}^{-1}$.
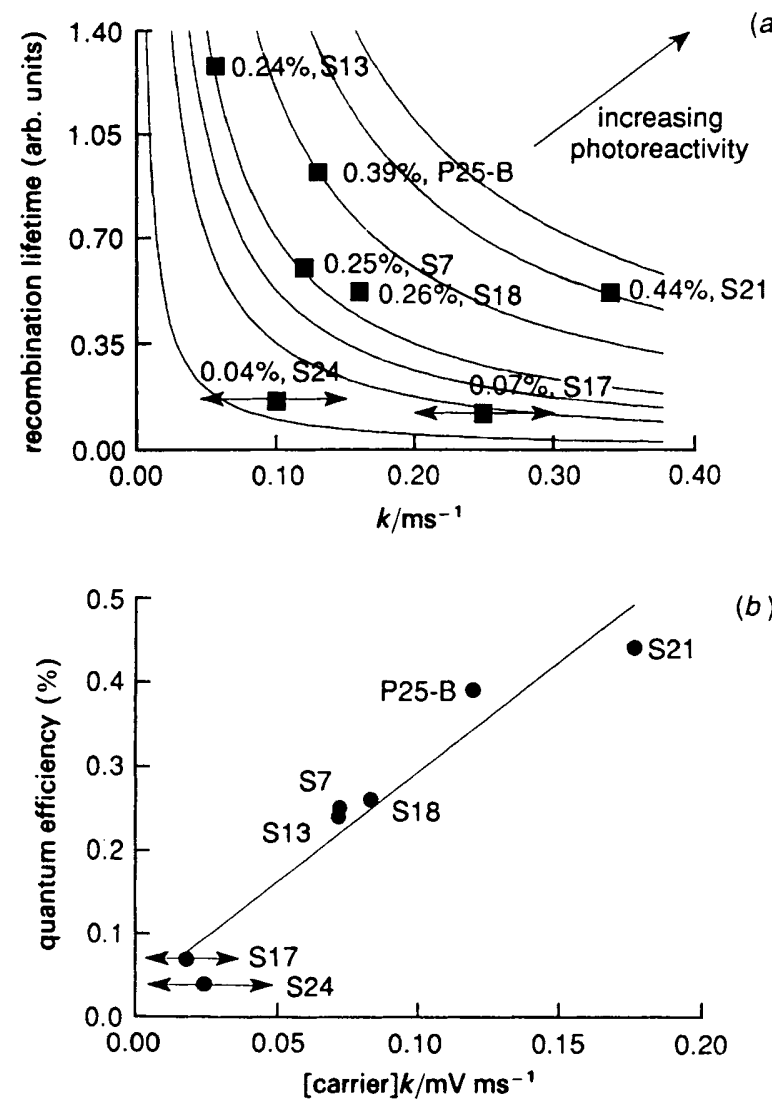

Fig. 9 (a) Contour plot of quantum efficiency as a function of recombination lifetime (see explanation in main text) and interfacial electron-transfer rate constant. (b) Linear transformation of contour plot. ed in Tables 1 and 3 . The contours drawn fit the function $C=x y$. A plot of $C$ vs. the product of $x$ and $y$ results in a straight line, as shown in Fig. $9(b)$ where $C$ is the quantum efficiency and $x y$ is the contour value, i.e. the product of the recombination lifetime and the interfacial electron-transfer rate constant, $k$. The data points for $\mathrm{S} 17$ and S24 are calculated using $k=0.15 \mathrm{~ms}^{-1}$ and the extrema of the arrows are calculated for $k=0.03 \mathrm{~ms}^{-1}$ and $k=0.30 \mathrm{~ms}^{-1}$. Fig. $9(b)$ demonstrates more clearly than Fig. $9(a)$ the correlations between photoreactivity and charge-carrier dynamics.

To investigate the effect of $\mathrm{HNO}_{3}, \mathrm{P} 25-\mathrm{A}$ was prepared by rotary evaporation from an acidic slurry $\left(\mathrm{HNO}_{3}, \mathrm{pH} 1.5\right)$ and was then supported in a trans-decalin paste for the conductivity measurements. In a separate preparation, P25-A was directly prepared as a paste in trans-decalin. The conductivity decays are shown in Fig. 10. It is apparent that the temporal behaviour of the coated and uncoated samples is similar. In addition, the conductivity decays of $\mathrm{Q}-\mathrm{TiO}_{2}$ and $\mathrm{Fe}^{\mathrm{III}}$-doped $\mathrm{Q}-\mathrm{TiO}_{2}$ are overlaid in Fig. 10. The TRMC measurements for these samples are summarized in Table 3.

\section{Discussion}

In previous papers, we proposed that the larger overpotentials in $\mathrm{Q}-\mathrm{TiO}_{2}$ vs. bulk-phase $\mathrm{TiO}_{2}$ should lead to higher quantum yields. ${ }^{10,11,58}$ However, the data in Fig. 4 clearly show that $\mathrm{Q}-\mathrm{TiO}_{2}$ is less photoreactive than P25-A. In similar experiments carried out with substrates representing a variety of postulated mechanistic pathways, including direct hole attack on $\mathrm{HCCl}_{3}$ and $\mathrm{DCA},{ }^{24}$ hydroxyl radical attack of 4-CP and PCP, ${ }^{27-31,59}$ and electron transfer to $\mathrm{CCl}_{4},{ }^{10,11,42,60}$ the quantum efficiencies ( $c f$. Table 1)
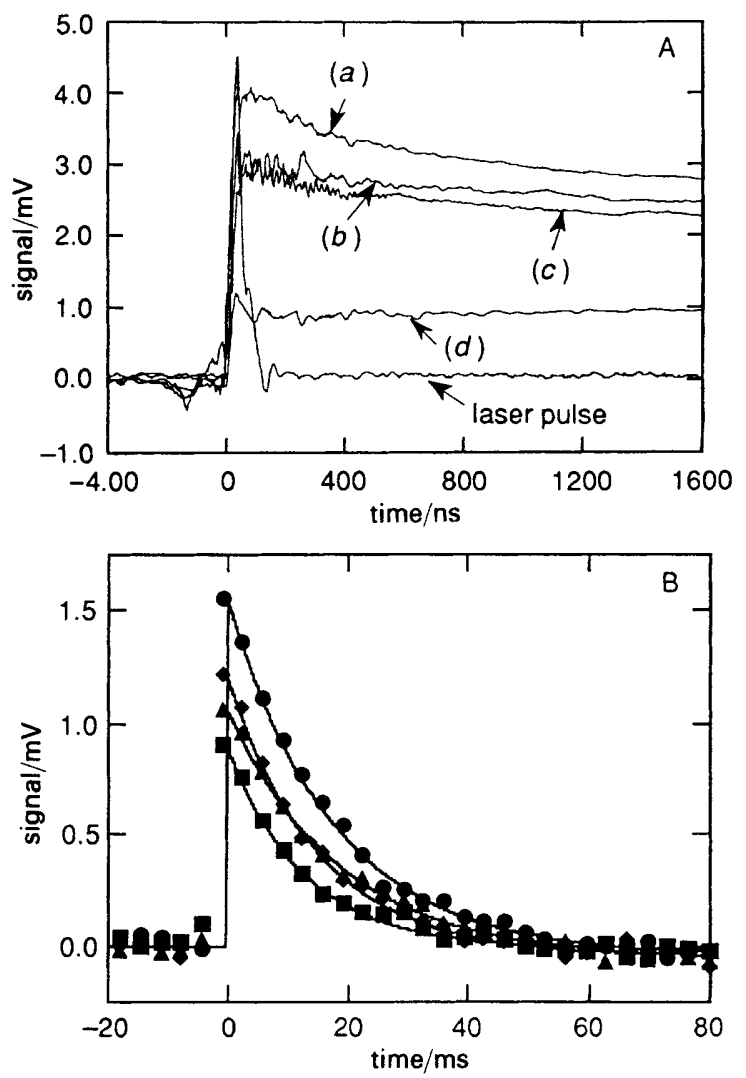

Fig. 10 Conductivity decays of P25-A (c), $\bullet$ Q- $\mathrm{TiO}_{2}(b), \boldsymbol{\Delta}$ and $\mathrm{Fe}^{\mathrm{III}}$-doped $\mathrm{Q}-\mathrm{TiO}_{2}($ d), $\mathbf{\square}$. Samples prepared by rotary evaporation from $\mathrm{HNO}_{3}\left(\mathrm{pH}^{1.5}\right)$ and supported in trans-decalin except for P25-A-no $\mathrm{NO}_{3}^{-}(a)$, , which was prepared without $\mathrm{HNO}_{3}$. A, 200 ns div. ${ }^{-1}$ timebase. $B, 10 \mathrm{~ms} \mathrm{div.}^{-1}$ timebase. 
obtained for $\mathrm{Q}-\mathrm{TiO}_{2}$ appear to be consistently lower than those obtained for bulk-phase P25. These data suggest several possibilities. On the one hand, the lower photoreactivity of $\mathrm{Q}-\mathrm{TiO}_{2}$ may be due to an increased rate of chargecarrier recombination. On the other hand, there may be substantial differences in the interfacial charge-transfer rates between Q- $\mathrm{TiO}_{2}$ and P25-A.

The differences between Q- $\mathrm{TiO}_{2}$ and P25-A are at least partially understood by considering the preparation methods that may result in more defect sites (trapping sites) and faster recombination rates in $\mathrm{Q}-\mathrm{TiO}_{2} . \mathrm{P} 25-\mathrm{A} \mathrm{TiO}_{2}$ is prepared in a high-temperature flame reactor and is thus expected to have fewer defects ${ }^{47,48}$ whereas $\mathrm{Q}^{-\mathrm{TiO}_{2}}$ is prepared by sol-gel techniques at much lower temperatures. Different surface morphologies (e.g. hydroxylation density) may also be expected and the interfacial charge-transfer rates may be controlled by the relative formation of surface complexes on Q$\mathrm{TiO}_{2}$ as compared to $\mathrm{P} 25-\mathrm{A}$.

The relationship between the charge-carrier recombination rate and quantum efficiency can be expressed as follows:

$$
\phi_{\text {transfer }}=\frac{\text { rate }_{\text {transfer }}}{\text { rate }_{\text {transfer }}+\text { rate }_{\text {recombination }}}
$$

If the charge-carrier recombination rate in $\mathrm{Q}-\mathrm{TiO}_{2}$ increases due to defects, then the quantum efficiency of interfacial charge transfer decreases and $\mathrm{Q}-\mathrm{TiO}_{2}$ should be less photoreactive than $\mathbf{P} 25$.

The observed conductivity decays in our TRMC experiments should yield the recombination rates of photogenerated free charge carriers. However, the TRMC response is influenced by other deactivation pathways such as interfacial charge transfer to adsorbed species. In these cases, the conductivity decays may be due to both recombination and charge transfer, and the data must be deconvoluted. ${ }^{34-38,40,41}$ In the absence of recombination or chargecarrier localization during the laser pulse, the conductivity measured after the laser pulse should be proportional to the number of free charge carriers:

$$
\Delta \sigma=q N\left(\mu_{\mathrm{e}^{-}}+\mu_{\mathrm{h}^{+}}\right)
$$

where $N$ is the number of adsorbed photons (if equal reflectivities and short penetration depths are assumed among the samples). The data of Fig. 5 are consistent with the prediction of eqn. (5) that the strength of the conductivity signal increases with the mobility of the charge carriers $\left(\sum \mu_{\mathrm{Zno}}=\right.$ $380 \mathrm{~cm}^{2} \quad \mathrm{~V}^{-1} \mathrm{~s}^{-1,54} \sum \mu_{\mathrm{CdS}}=300^{34}$ and $\left.\sum \mu_{\mathrm{TiO}_{2}}=1^{35}\right)$. From eqn. (3) we see that

$$
\Delta V=(q N V A / n)\left(\mu_{\mathrm{e}^{-}}+\mu_{\mathrm{h}^{+}}\right)
$$

Eqn. (6) predicts a linear correlation between the post-pulse conductivity, $\Delta V$, and the sum of the mobilities with a corresponding slope of $(q N V / n) A$. Using this relationship, our specific apparatus constant, $A$, can be evaluated. A linear fit applied to the data in Fig. 5 yields a slope of $0.28 \mathrm{mV} / \mathrm{cm}^{2}$ $\left.\mathrm{V}^{-1} \mathrm{~s}^{-1}\right), r^{2}=0.81$ and $A=1.1 \times 10^{3} \mathrm{~S}^{-1}$. Since $r^{2}<1$, there is a high probability that localization (i.e. recombination or interfacial charge transfer) has taken place during the laser pulse. Thus, we consider the above $A$ value to be a lower estimate.

\section{Photoelectrochemical Mechanisms}

We propose the following four processes for charge-carrier recombination: $:^{59,61-63}$

charge-carrier generation

$$
\mathrm{TiO}_{2}+h v \stackrel{k_{\mathrm{II}}}{\longrightarrow} \mathrm{e}_{\mathrm{cb}}{ }^{-}+\mathrm{h}_{\mathrm{vb}}{ }^{+}
$$

direct and indirect charge-carrier trapping

$$
\begin{aligned}
& \mathrm{e}_{\mathrm{cb}}{ }^{-}+\mathrm{T}_{\mathrm{e}^{-}} \stackrel{k_{\mathrm{III}}}{\longrightarrow} \mathrm{e}_{\mathrm{T}}{ }^{-} \\
& \mathrm{h}_{\mathrm{vb}}{ }^{+}+\mathrm{T}_{\mathrm{h}^{+}} \stackrel{k_{\mathrm{IV}}}{\longrightarrow} \mathrm{h}_{\mathrm{T}}{ }^{+}
\end{aligned}
$$

charge-carrier recombination

$$
\begin{aligned}
& \mathrm{e}_{\mathrm{cb}}{ }^{-}+\mathrm{h}_{\mathrm{vb}}{ }^{+} \stackrel{{ }^{k \mathrm{v}}}{\longrightarrow} \mathrm{TiO}_{2} \\
& \mathrm{e}_{\mathrm{cb}}{ }^{-}+\mathrm{h}_{\mathrm{T}}{ }^{+} \stackrel{{ }_{\mathrm{vI}}}{\longrightarrow} \mathrm{TiO}_{2}+\mathrm{T}_{\mathrm{h}^{+}} \\
& \mathrm{h}_{\mathrm{vb}}{ }^{+}+\mathrm{e}_{\mathrm{T}}{ }^{-} \stackrel{{ }_{\mathrm{v} I I I}}{\longrightarrow} \mathrm{TiO}_{2}+\mathrm{T}_{\mathrm{e}^{-}}
\end{aligned}
$$

interfacial charge transfer

$$
\begin{aligned}
& \mathrm{e}_{\mathrm{cb}}{ }^{-}+\mathrm{O} \stackrel{{ }^{k \mathrm{vII}}}{\longrightarrow} \mathrm{O}^{-} \\
& \mathrm{e}_{\mathrm{T}}{ }^{-}+\mathrm{O} \stackrel{{ }_{\mathrm{kx}}}{\longrightarrow} \mathrm{O}^{-}+\mathrm{T}_{\mathrm{e}^{-}} \\
& \mathrm{h}_{\mathrm{vb}}{ }^{+}+\mathrm{R} \stackrel{{ }^{k} \mathrm{x}}{\longrightarrow} \mathrm{R}^{+} \\
& \mathrm{h}_{\mathrm{T}}^{+}+\mathrm{R} \stackrel{{ }_{\mathrm{kxI}}}{\longrightarrow} \mathrm{R}^{+}+\mathrm{T}_{\mathrm{h}^{+}}
\end{aligned}
$$

where $e_{T}{ }^{-}$is a trapped electron, $\mathrm{h}_{\mathrm{T}}{ }^{+}$is a trapped hole, $\mathrm{T}_{\mathrm{e}^{-}}$is an empty electron trap, $T_{h^{+}}$is an empty hole trap, $O$ is an electron acceptor (oxidant) and $R$ is an electron donor (reductant). At present, we believe that the electron is trapped in a surface $\mathrm{Ti}^{\mathrm{III}}$ site ${ }^{42,64,65}$ while the hole is trapped in a surface hydroxy group. ${ }^{42,66,67}$

Based on this mechanism we can write an equation for the change in microwave conductivity as follows:

$$
\begin{aligned}
\frac{\mathrm{d} \sigma}{\mathrm{d} t}=\mu_{\mathrm{e}_{\mathrm{cb}}-} \frac{\mathrm{d}\left[\mathrm{e}_{\mathrm{cb}}{ }^{-}\right]}{\mathrm{d} t}+ & \mu_{\mathrm{e}^{-}} \frac{\mathrm{d}\left[\mathrm{e}_{\mathrm{T}}{ }^{-}\right]}{\mathrm{d} t} \\
& +\mu_{\mathrm{h}_{\mathrm{vb}}+} \frac{\mathrm{d}\left[\mathrm{h}_{\mathrm{vb}}{ }^{+}\right]}{\mathrm{d} t}+\mu_{\mathrm{h}^{+}} \frac{\mathrm{d}\left[\mathrm{h}_{\mathrm{T}}{ }^{+}\right]}{\mathrm{d} t}
\end{aligned}
$$

For $\mathrm{ZnO}, \mu_{\mathrm{e}_{\mathrm{T}}}\left(\mathrm{d}\left[\mathrm{e}_{\mathrm{T}^{-}}{ }^{-}\right] / \mathrm{d} t\right)$ and $\mu_{\mathrm{h}_{\mathrm{T}}}\left(\mathrm{d}\left[\mathrm{h}_{\mathrm{T}}{ }^{+}\right] / \mathrm{d} t\right)$ can be omitted from eqn. (7) owing to the high mobility of the free chargecarriers. However, in the case of $\mathrm{TiO}_{2}$, these terms must be included since shallowly trapped and free electrons have comparable mobilities. Even though the observed microwave conductivity signal is due to a mixture of species and mobilities, we believe that the observed conductivity as shown in Fig. 8 and 10 can be assigned primarily to electrons

$$
\text { (i.e. } \mu_{\mathrm{e}_{\mathrm{cb}^{-}}} \frac{\mathrm{d}\left[\mathrm{e}_{\mathrm{cb}}{ }^{-}\right]}{\mathrm{d} t} \text { and } \mu_{\mathrm{e}^{-}} \frac{\mathrm{d}\left[\mathrm{e}_{\mathrm{T}}{ }^{-}\right]}{\mathrm{d} t} \text { ). }
$$

In order to explain the timescales for the microwave conductivity decays shown in Fig. 8 and 10, a mechanism that includes interfacial charge transfer must be invoked because recombination is complete in $c a .100 \mathrm{~ns}$ in the absence of interfacial charge transfer ${ }^{62,68}$ In order for the kinetics of the charge transfer to compete with recombination processes internal to the $\mathrm{TiO}_{2}$ particle, interfacial charge transfer of at least one carrier should occur within several ns. ${ }^{68}$ Therefore, only one charge-carrier type (i.e. holes or electrons) should be present in the particle after $100 \mathrm{~ns}$. Because hole transfer often takes place within ns while electron transfer takes place over the timescale of $\mathrm{ns}$ to $\mathrm{ms},{ }^{42,64,69}$ we conclude that electrons give rise to the measured TRMC conductivity.

The overall quantum efficiency for interfacial charge transfer is determined by two critical processes: the competition between carrier recombination and trapping (ps to ns) followed by the competition between carrier recombination and interfacial charge transfer ( $\mu \mathrm{s}$ to $\mathrm{ms}$ ). The measurement of the 
conductivity at 100 ns gives information on fast recombination while the measurement at longer timescales yields information on interfacial charge transfer. The fall-off in the remaining charge carriers at $100 \mathrm{~ns}$ with increasing injection level is shown in Fig. 7. The apparent discontinuity at $6 \mathrm{~mJ}$ suggests that a higher-order channel is opened with fewer residual charge carriers at $100 \mathrm{~ns}$. These results are consistent with the inverse relationship observed between quantum efficiency for $\mathrm{CHCl}_{3}$ oxidation and light intensity shown in Fig. $6 .{ }^{16,24}$ Based on these results, we believe that the recombination lifetime of charge carriers is inversely proportional to the conductivity at $100 \mathrm{~ns}$.

An increase in either the recombination lifetime of charge carriers or the interfacial electron-transfer rate constant is expected to result in higher quantum efficiencies for $\mathrm{CW}$ photolysis. The samples S7-P25 are observed to follow this relationship in Fig. 9(a). The linear transformation of the contour plot in Fig. $9(b)$ makes the correlation more apparent. Fig. $9(a)$ suggests S21 owes its high photoreactivity to a fast interfacial electron-transfer rate constant whereas P25 has a high photoreactivity due to slow recombination. Bickley et al. have suggested that the anatase-rutile structure of $\mathrm{P} 25$ promotes charge-pair separation and inhibits recombination. ${ }^{47}$ The different recombination lifetimes and interfacial electron-transfer rate constants may be due to the different methods of preparation of the samples that result in different crystal defect structures and surface morphologies.

A conduction band electron is thermodynamically capable of reducing $\mathrm{H}^{+}, \mathrm{NO}_{3}{ }^{-}, \mathrm{O}_{2}$ and oxidized trans-decalin radicals $\left(\mathrm{T}^{+}\right)$while a valence band hole is sufficiently powerful to oxidize trans-decalin. The signal strength observed in Fig. $10(a)$ for $\mathrm{P} 25-\mathrm{A}$ in the presence of $\mathrm{HNO}_{3}$ is reduced relative to the uncoated P25-A. This relative change may be due to a fast reduction of $\mathrm{H}^{+}$or $\mathrm{NO}_{3}{ }^{-}$in the first monolayer or to an inhibition of hole transfer which results in greater chargecarrier recombination. However, the time dependence of the conductivity decay appears to be unchanged in the presence of $\mathrm{HNO}_{3}$. In contrast, the fast timescale recombination observed for $\mathrm{Q}-\mathrm{TiO}_{2}$ and $\mathrm{P} 25-\mathrm{A}\left(\mathrm{NO}_{3}{ }^{-}\right)$appears to be similar as shown in Table 2. This observation suggests that a similar number of defects are present in each material. In general, the time-dependent changes summarized in Fig. 10 indicate that electrons undergo interfacial charge transfer more slowly for $\mathrm{Q}^{-\mathrm{TiO}_{2}}\left(k=0.052 \mathrm{~ms}^{-1}\right)$ than for P25-A $\left(k=0.065 \mathrm{~ms}^{-1}\right)$. This result is consistent with the observed lower steady-state quantum yields (Table 1).

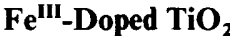

EPR and transient absorption studies have shown that $\mathrm{Fe}^{\mathrm{III}}$ doping in colloidal $\mathrm{TiO}_{2}$ acts by trapping holes as $\mathrm{Fe}^{\mathrm{IV}}$ within several ns of excitation and that slow recombination takes place by tunnelling from electrons trapped at surface $\mathrm{Ti}^{\mathrm{III}}$ sites to holes trapped at bulk-phase $\mathrm{Fe}^{\mathrm{IV}}$ sites. ${ }^{4,70}$ The $\mathrm{Fe}^{\mathrm{III}}$ dopant thus acts to inhibit charge-carrier recombination. These processes can be written in terms of reactions (XII) and (XIII), respectively:

$$
\begin{aligned}
\mathrm{Fe}^{\mathrm{III}}+\mathrm{h}^{+} \stackrel{k_{\mathrm{XII}}}{\longrightarrow} \mathrm{Fe}^{\mathrm{IV}} \\
\mathrm{Fe}^{\mathrm{IV}}+\mathrm{Ti}^{\mathrm{III}} \stackrel{k_{\mathrm{XIII}}}{\longrightarrow} \mathrm{TiO}_{2}-\mathrm{Fe}^{\mathrm{III}}
\end{aligned}
$$

The oxidation of the sorbed electron donor is written as:

$$
\mathrm{Fe}^{\mathrm{IV}}+\mathrm{R} \stackrel{k_{\mathrm{xIV}}}{\longrightarrow} \mathrm{TiO}_{2}-\mathrm{Fe}^{\mathrm{III}}+\mathrm{R}^{+}
$$

A flat microwave signal in Fig. 10 is consistent with the inhibition of carrier recombination within the iron-doped sample.
However, the conductivity signal at $100 \mathrm{~ns}$ is weaker for the $\mathrm{Fe}^{\mathrm{III}}$-doped sample than for the undoped sample. The mobility of the electrons in $\mathrm{Fe}^{\mathrm{II}}$-doped $\mathrm{Q}-\mathrm{TiO}_{2}$ may be significantly reduced because $\mathrm{Fe}^{\mathrm{III}}$ is present at a concentration of $2.9 \times 10^{20} \mathrm{~cm}^{-3}$. For example, the mobility of an electron in silicon drops from $1100 \mathrm{~cm}^{2} \mathrm{~V}^{-1} \mathrm{~s}^{-1}$ to $100 \mathrm{~cm}^{2} \mathrm{~V}^{-1} \mathrm{~s}^{-1}$ in a similary doped lattice. ${ }^{71}$ The net effect is a lower initial microwave conductivity for $\mathrm{Fe}^{\mathrm{III}}$-doped $\mathrm{Q}-\mathrm{TiO}_{2}$

In summary, we believe the hole, which is trapped at an $\mathrm{Fe}^{\mathrm{IV}}$ site, is transferred to an adsorbed substrate on a submillisecond timescale while the interfacial electron transfer occurs on the ms scale [eqn. (VIII) and (IX)]. As a result, we predict higher steady-state quantum efficiencies for $\mathrm{Fe}^{\text {III }}$. doped Q- $\mathrm{TiO}_{2}$. This prediction is supported by results shown in Fig. 4.

\section{Conclusions}

After pulse laser excitation of charge carriers, holes which escape band-gap recombination are transferred to the sorbed electron donor trans-decalin within ns. The TRMC conductivity signals are due to electrons remaining in the semiconductor lattice after hole transfer. The resultant interfacial electron transfer takes place over ms and appears to be faster for $\mathrm{P} 25$ than for Q-TiO 2 . The slower electron-transfer rates observed for $\mathrm{Q}-\mathrm{TiO}$, are consistent with the lower steadystate quantum yields. $\mathrm{Fe}^{\mathrm{III}}$ doped into the $\mathrm{Qi}-\mathrm{TiO}_{2}$ matrix serves to trap holes as $\mathrm{Fe}^{\mathrm{IV}}$ and thus reduces charge-carrier recombination, which in turn results in increased quantum efficiencies. The correlations observed between quantum efficiencies and charge-carrier dynamics emphasize the importance of the interfacial charge-transfer rate constant and the charge-carrier recombination lifetime as contributing factors to $\mathrm{TiO}_{2}$ photoreactivity.

We are indebted to Prof. Nathan S. Lewis for the loan of microwave components, to Prof. Geoffrey A. Blake for the use of the excimer laser and to Dr. Detlef W. Bahnemann for providing the Sachtleben Chemie samples. We are grateful to ARPA and ONR \{NAV 5 HFMN N0001492J1901\} for financial support. S.M. is supported by a National Defense Science and Engineering Graduate Fellowship. H.H. wishes to thank NATO/DAAD for financing a research vist at the California Institute of Technology. Nicole Peill, Dr. Amy Hoffman and Dr. Andreas Termin provided valuable support and stimulating discussion.

\section{References}

1 L. Brus, Appl. Phys. A., 1991, 53, 465.

2 H. Weller, Adv. Mater., 1993, 5, 88 .

3 M. Grätzel, Nature (London), 1991, 349, 740

4 H. Weller, Angew. Chem., 1993, 32, 41

5 A. T. Henglein, Curr. Chem., 1988, 143, 113

6 P. V. Kamat, Chem. Rev., 1993, 93, 267.

7 R. A. Marcus and N. Sutin, Biochim. Biophys. Acta, 1985, 811, 265.

8 R. A. Marcus, J. Phys. Chem., 1990, 94, 1050.

9 N. S. Lewis, Annu. Rev. Phys., 1991, 42, 543.

10 A. J. Hoffman, G. Mills, H. Yee and M. R. Hoffmann, J. Phys. Chem., 1992, 96, 5546.

11 A. J. Hoffman, H. Yee, G. Mills and M. R. Hoffmann, J. Phys Chem., 1992, 96, 5540.

12 Photocatalysis and Environment: Trends and Applications, ed. M. Schiavello, Kluwer, Dordrecht, 1988.

13 Homogeneous and Heterogeneous Photocatalysis, ed. E. Pelizzetti and N. Serpone, Reidel, Dordrecht, 1986.

14 Photoelectrochemistry, Photocatalysis and Photoreactors, ed. M. Schiavello, Reidel, Dordrecht, 1985.

15 Photocatalysis: Fundamentals and Applications, ed. N. Serpone and E. Pelizzetti, Wiley, New York, 1989. 
16 A. J. Hoffman, E. R. Carraway and M. R. Hoffmann, Environ. Sci. Technol., 1994, 28, 776.

17 M. Anpo, T. Shima, S. Kodama and Y. Kubokawa, J. Phys. Chem., 1987, 91, 4305.

18 J. M. Nedeljkovic, M. T. Nenadovic, O. I. Micic and A. J. Nozik, J. Phys. Chem., 1986, 90, 12.

19 Y. Nosaka, N. Ohta and H. Miyama, J. Phys. Chem., 1990, 94, 3752.

20 P. Giuseppe, C. H. Langford, J. Vichova and A. Vleck, J. Photochem. Photobiol. A: Chem., 1993, 75, 67.

21 W. Lee, Y-M. Gao, K. Dwight and A. Wold, Mater. Res. Bull., 1992, 27, 685 .

22 S. Nishimoto, B. Ohtani, H. Kajiwara and T. Kagiya, J. Chem. Soc., Faraday Trans. I, 1985, 81, 61 .

23 B. C. Faust, M. R. Hoffmann and D. W. Bahnemann, J. Phys. Chem., 1989, 93, 6371.

24 C. Kormann, D. W. Bahnemann and M. R. Hoffmann, Environ Sci. Technol., 1991, 25, 494.

25 G. Mills and M. R. Hoffmann, Environ. Sci. Technol., 1993, 27, 1681 .

26 M. Barbeni, E. Pramauro and E. Pelizzetti, Chemosphere, 1985 14, 195

27 H. Al-Ekabi, N. Serpone, E. Pelizzetti and C. Minero, Langmuir, $1989,5,250$.

28 G. Al-Sayyed, J. C. D'Oliveira and P. Pichat, J. Photochem. Photobiol. A: Chem., 1991, 58, 99.

29 M. Barbeni, E. Pramauro, E. Pelizzetti, E. Brogarello, M Grätzel and N. Serpone, Nouv. J. Chem., 1984, 8, 547.

30 A. P. Y. Durand, D. Brattan and R. G. Brown, Chemosphere, 1992, 25, 783 .

31 A. Mills, S. Morris and R. Davies, J. Photochem. Photobiol. A Chem., 1993, 70, 183 .

32 M. Kunst and G. Beck, J. Appl. Phys., 1986, 60, 3558.

33 J. M. Warman and M. P. de Haas, in Pulse Radiolysis, ed. Y. Tabata, CRC Press, Boca Raton, FL, 1991, ch. 6.

34 J. M. Warman, M. P. de Haas, S. W. F. M. van Hovell tot Westerflier, J. J. M. Binsma and Z. I. Kolar, J. Phys. Chem., 1989, 93 5895.

35 J. M. Warman, M. P. de Haas, P. Pichat, T. P. M. Koster, E. A. van der Zouwen-Assink, A. Mackor and R. Cooper, Radiat. Phys. Chem., 1991, 37, 433.

36 R. W. Fessenden and P. V. Kamat, Chem. Phys. Lett., 1986, 123, 233.

37 J. M. Warman, M. P. de Haas, M. Grätzel and P. P. Infelta, Nature (London), 1984, 310, 306

38 J. M. Warman, M. P. de Haas, P. Pichat and N. Serpone, J. Phys. Chem., 1991, 95, 8858.

39 S. Ramo, J. R. Whinnery and T. van Duzer, Fields and Waves in Communication Electronics, Wiley, New York, 1984

40 K. M. Schindler and M. Kunst, J. Phys. Chem., 1990, 94, 8222

41 J. M. Warman, M. P. de Haas and H. M. Wentinck, Radiat Phys. Chem., 1989, 34, 581.

42 D. Bahnemann, A. Henglein, J. Lilie and L. Spanhel, J. Phys. Chem., 1984, 88, 709 .
43 J. Moser, M. Grätzel and R. Gallay, Helv. Chim. Acta, 1987, 70, 1596.

44 D. W. Bahnemann, Isr. J. Chem., 1993, 33, 115.

45 Powder Diffraction File, Sets 21-22; JCPDS: Swarthmore, 1980 vol. PD1S-22iRB, pp. 21-1272.

46 B. D. Cullity, Elements of X-Ray Diffraction, Addison-Wesley, Reading, 2nd edn., 1978, p. 102.

47 R. I. Bickley, T. Gonzalez-Carreno, J. S. Lees, L. Palmisano and R. J. D. Tilley, J. Solid State Chem., 1991, 92, 178

48 Degussa Technical Bulletin, No. 56, 1990.

49 D. W. Bahnemann, personal communication

50 H. G. Heller and J. R. Langan, J. Chem. Soc., Perkin Trans. 2, $1981,341$.

51 P. P. Infelta, M. P. de Haas and J. M. Warman, Radiat. Phys. Chem., 1977, 10, 353.

52 R. W. Fessenden, P. M. Carton, H. Shimamori and J. C. Scalano, J. Phys. Chem., 1982, 86, 3803.

53 M. Kunst and A. Sanders, Semicond. Sci. Technol., 1992, 7, 51.

54 S. M. Sze, in Physics of Semiconductor Devices, Wiley, New York, 2nd edn., 1981.

55 H. O. Finklea, in Semiconductor Electrodes, ed. H. O. Finklea, Elsevier, New York, 1988, p. 52.

56 M. Anderman and J. H. Kennedy, in Semiconductor Electrodes, ed. H. O. Finklea, Elsevier, New York, 1988, p. 153

57 N. F. Mott and E. A. Davis, in Electronic Processes in NonCrystalline Materials, Clarendon Press, Oxford, 1971, pp. 117ff.

58 D. W. Bahnemann, C. Kormann and M. R. Hoffmann, J. Phys Chem., 1987, 91, 3789.

59 N. Serpone, D. Lawless, R. Terzian and D. Meisel, in Electrochemistry in Colloids and Dispersions, ed. R. A. Mackay and J. Texter, VCH, New York, 1992, ch. 30, pp. 399-416.

60 M. Prairie, L. R. Evans, B. M. Stange and S. L. Martinez, Environ. Sci. Technol., 1993, 27, 1776.

61 C. S. Turchi and D. F. Ollis, J. Catal., 1990, 122, 178

62 G. Rothenberger, J. Moser, M. Grätzel, N. Serpone and D. K. Sharma, J. Am. Chem. Soc., 1985, 107, 8054

63 C. Boxall and G. H. Kelsall, J. Chem. Soc., Faraday Trans., $1991,87,3547$.

64 U. Kölle, J. Moser and M. Grätzel, Inorg. Chem., 1985, 24, 2253.

65 R. F. Howe and M. Grätzel, J. Phys. Chem., 1985, 89, 4495.

66 D. Lawless, N. Serpone and D. Meisel, J. Phys. Chem., 1991, 95, 5166.

67 O. I. Micic, Y. Zhang, K. R. Cromack, A. D. Trifunac and M. C. Thurnauer, J. Phys. Chem., 1993, 97, 7277.

68 A. Henglein, Ber. Bunsenges. Phys. Chem., 1982, 86, 241.

69 D. Bahnemann, A. Henglein and L. Spanhel, Faraday Discuss. Chem. Soc., 1984, 78, 151.

70 M. Grätzel and R. F. Howe, J. Phys. Chem., 1990, 94, 2566.

71 R. F. Pierret, Semiconductor Fundamentals, Addison-Wesley, New York, 2nd edn., 1989, vol. 1

Paper 4/02296C; Received 18th April, 1994 